\title{
Fixed-dose combinations at the front line of multimodal pain management: perspective of the nurse-prescriber
}

This article was published in the following Dove Press journal:

Nursing: Research and Reviews

I February 2013

Number of times this article has been viewed

\author{
Joanne O'Brien' \\ Joseph V Pergolizzi Jr² \\ Mart van de Laar $^{3}$ \\ Hans-Ulrich Mellinghoff ${ }^{4}$ \\ Ignacio Morón Merchante ${ }^{5}$ \\ Srinivas Nalamachu ${ }^{6}$ \\ Serge Perrot ${ }^{7}$ \\ Robert B Raffa ${ }^{8}$ \\ 'Department of Pain Medicine, \\ Beaumont Hospital, Beaumont, \\ Dublin, Ireland; ${ }^{2}$ Department of \\ Medicine, Johns Hopkins University \\ School of Medicine, Baltimore, \\ MD; Association of Chronic Pain \\ Patients, Houston, TX; Department \\ of Pharmacology, Temple University \\ School of Medicine, Philadelphia, \\ PA, USA; ${ }^{3}$ Arthritis Center Twente, \\ Enschede, The Netherlands; \\ ${ }^{4}$ Department of Endocrinology, \\ Diabetology and Osteology, \\ Kantonsspital St Gallen, Switzerland; \\ ${ }^{5}$ Centro de Salud Universitario Goya, \\ Madrid, Spain; ${ }^{6}$ Kansas University \\ Medical Center, Kansas City, and \\ International Clinic Research, \\ Leawood, KS, USA; ${ }^{7}$ Service de \\ Médecine Interne et Consultation de \\ la Douleur, Hôpital Hotel Dieu, Paris \\ Descartes University, Paris, France; \\ ${ }^{8}$ Department of Pharmaceutical \\ Sciences, Temple University School \\ of Pharmacy, Philadelphia PA, USA
}

Correspondence: Joanne O'Brien Pain Nurse Specialist, Department of Pain Medicine, Beaumont Hospital, Beaumont, Dublin 9, Ireland

$\mathrm{Tel}+353$ । 8528380

Fax $+353 \mid 8528380$

Email joanneobrienl6@hotmail.com

\begin{abstract}
Pain should be treated promptly and effectively to restore the patient to full function, avoid pain chronification, and preserve quality of life. A recent pain specialists' meeting discussed the use of different pharmacological treatment options, such as topical analgesics, nonopioid agents (such as paracetamol and nonsteroidal anti-inflammatory drugs), weak and strong opioids, and fixed-dose combination products in the management of moderate to severe pain from different etiologies. One of the topics discussed in, and subsequent to, this meeting was the role of fixed-dose combination products for nurse-prescribers who are in many ways at the front line of managing both acute and chronic pain syndromes. The panel agreed that proper product selection should take into account the patient's age, condition, type of pain, and comorbidities, as well as balance safety with effectiveness. Although nurse-prescribers need to be aware of cumulative paracetamol dosing, fixed-dose combination products, such as tramadol-paracetamol, may offer important advantages, eg, by providing opioid-sparing without sacrificing efficacy.
\end{abstract}

Keywords: tramadol, paracetamol, fixed-dose combination analgesics, pain management

\section{Background}

Pain is a common health problem imposing a substantial burden on the afflicted individual and society. ${ }^{1}$ In the US, more individuals suffer from chronic pain than from diabetes, heart disease, and cancer combined, ${ }^{2}$ and one in five Europeans is afflicted by moderate-to-severe chronic pain lasting 6 months or more. ${ }^{3}$ Pain prevalence in the elderly is high; ${ }^{4}$ indeed, the aging population in the developed nations strongly suggests that chronic pain will become increasingly prevalent, problematic, and expensive.

Acute pain is the normal and expected adaptive response to noxious stimuli and diminishes as the body heals, whereas chronic pain is more complex and maladaptive, and involves altered pain perception. Acute pain may transition to chronic pain in a process known as chronification, which involves sensitization of the central nervous system. Chronic pain is often defined simplistically as pain that persists for more than 3 or 6 months, but this definition may be outmoded and cause us to view pain incorrectly, ie, to treat chronic pain as a form of prolonged pain, when it actually involves different mechanisms. ${ }^{5}$ Chronic pain may be entirely nociceptive, neuropathic (ie, as a direct consequence of a lesion or disease affecting the somatosensory system), ${ }^{6}$ or nociceptive with a neuropathic component (Figure 1). A well known example of this so-called mixed-pain is low back pain. ${ }^{7}$

Pain is one of the main reasons patients seek health care services. ${ }^{8}$ Common pain syndromes in general health care are acute or chronic musculoskeletal pain, headache, 




Figure I Although chronic pain is often defined as pain that persists for 3 or 6 months, it is actually clinically and biologically distinct from acute pain. Some examples of the different pain types are given in the chart.

Copyright @ 2012. John Wiley and Sons. Reprinted with permission from Pergolizzi J, Alegre C, Blake D, et al. Current considerations for the treatment of severe chronic pain: the potential for tapentadol. Pain Pract. 2012;12:290-306. ${ }^{129}$

Abbreviations: CRPS, complex regional pain syndrome; $\mathrm{PHN}$, postherpetic neuralgia.

post surgical pain, and scar pain. As a result of an aging population, nurse-prescribers often have an elderly clientele, therefore "wear and tear" indications, such as low back pain and osteoarthritis, and the pain associated with these conditions, is frequently encountered. Table 1 lists the most common indications encountered by nurse-prescribers.

As shown in Figure 1, pain syndromes belong to different pain types and might thus require different treatment approaches. Pharmacological options include topical pain relievers, nonopioid agents (such as aspirin, paracetamol [acetaminophen], and nonsteroidal anti-inflammatory drugs [NSAIDs]), and opioids acting on the ascending or descending pain pathways (Figure 2). It should be noted that, depending on the country, not all nurse-prescribers have prescribing rights for strong opioids (eg, in Ireland, palliative care nurses are able to prescribe strong opioids, such as morphine or fentanyl, but pain management nurses are only able to prescribe morphine for pain due to trauma or myocardial infarction).

Fixed-dose analgesic combinations combine two or more analgesic agents in a single tablet. Ideally, the two agents have complementary mechanisms of action, and may interact with each other in an additive (agent + agent) or synergistic way (where the results are greater than the sum of the parts). ${ }^{9}$ Possible advantages of fixed-dose combination products are dosing convenience, reduction of pill burden, the potential for greater patient adherence and, in the case of fixed-dose combination products involving an opioid and a nonopioid agent, opioidsparing effects and fewer side effects due to the reduced doses of each single substance. The possible role of the fixed-dose tramadol-paracetamol combination for pain relief in patients seen by nurse-prescribers is discussed here.

\section{Meeting details}

A consensus meeting attended by all authors of this publication was held on November 20, 2010 in Paris, France, to discuss the management of moderate to severe pain from different etiologies using different pharmacological treatment options, including the fixed-dose tramadol-paracetamol analgesic combination (Ixprim ${ }^{\circledR}$, Zaldiar ${ }^{\circledR}$ or Ultracet $^{\circledR}$ ). Presentations by four of the authors were followed by a

Table I Pain syndromes frequently encountered by nurseprescribers

\footnotetext{
- Musculoskeletal pain

- Back pain of unknown origin

- Osteoarthritis

- Rheumatoid arthritis

- Disc herniation

- Headache/migraine

- Postsurgical pain/scar pain

- Wound pain

- Cancer pain

- Neuropathic pain

- Visceral pain
} 


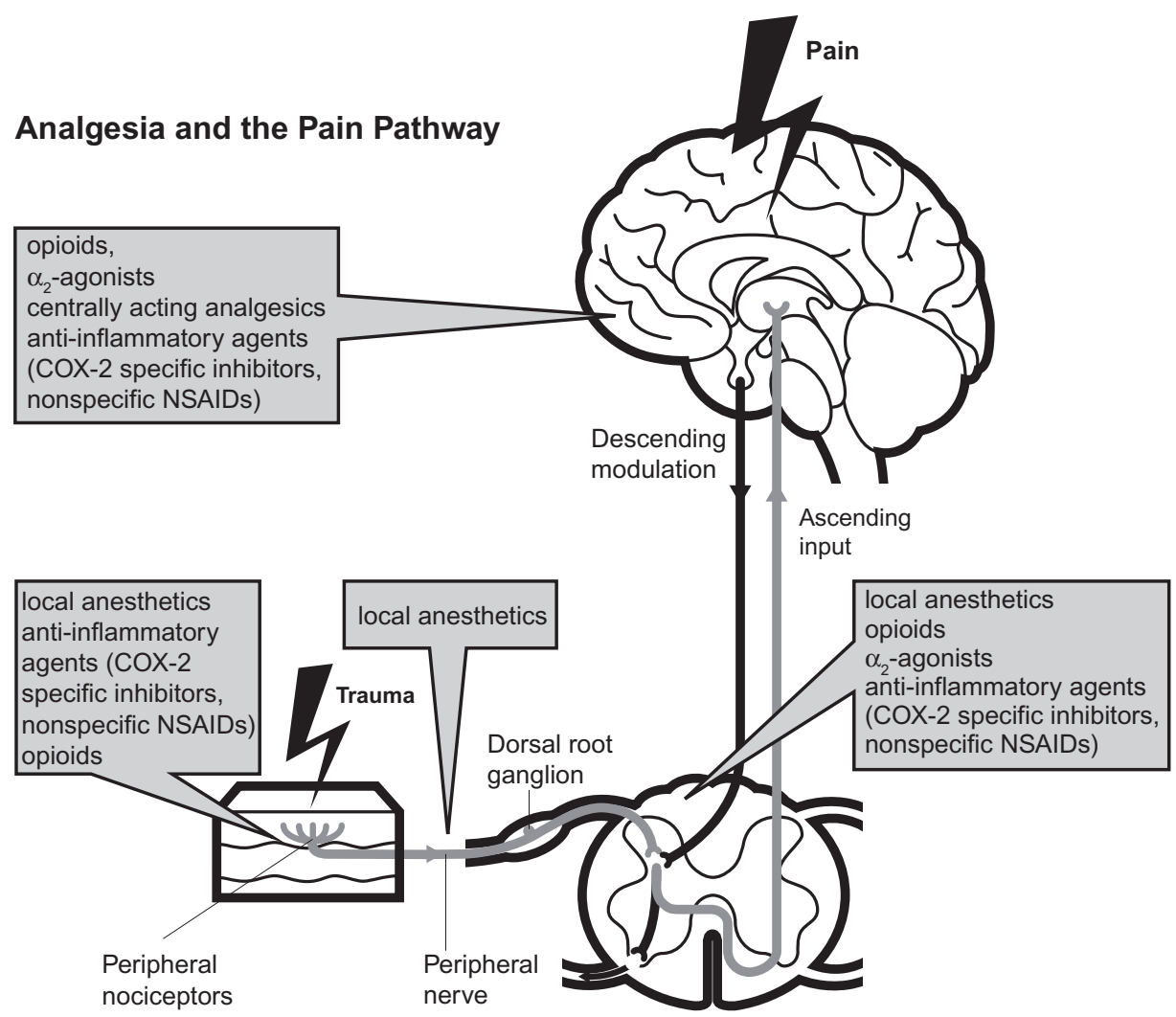

Figure 2 Analgesia and the pain pathway.

Copyright (C) 2012. John Wiley and Sons. Reprinted with permission from Pergolizzi J, Alegre C, Blake D, et al. Current considerations for the treatment of severe chronic pain: the potential for tapentadol. Pain Pract. 2012;12:290-306. ${ }^{12}$

Abbreviations: COX, cyclooxygenase; NSAIDs, nonsteroidal anti-inflammatory drugs.

group discussion and review of pain management issues and available guidelines/recommendations based on the clinical experiences of the participants. Subsequent to the meeting, the panelists discussed specific clinical issues in pain, including the role of fixed-dose combination products for nurse-prescribers, who in many ways are at the front line of managing both acute and chronic pain syndromes. Their final consensus is summarized in this publication.

\section{Pain and quality of life}

Chronic pain has a devastating effect on the lives of patients. Among chronic pain patients who suffered from pain $\geq 5$ (on a 10-point numeric rating scale of 1 to 10 with 10 the worst pain imaginable) for 6 months or more, $21 \%$ had been diagnosed with pain-related depression, $61 \%$ were unable or less able to work outside the home, and about one-third were not receiving any pain treatment. ${ }^{3}$ Pain-related depression has been correlated with decreased quality of life in chronic pain patients, ${ }^{10}$ and the severity of chronic pain was shown to correlate significantly with reduced health-related quality of life in adults ${ }^{11}$ and adolescents. ${ }^{12}$ However, multiple regression analysis of data from a recent study of heterogeneous chronic pain patients found pain catastrophizing to be a more important predictor of low quality of life than pain severity. ${ }^{13}$ Among migraine sufferers, the frequency of migraine episodes also correlated inversely with poor health-related quality of life scores. ${ }^{14} \mathrm{~A}$ review of 52 quality-of-life studies conducted among patients with six different types of neuropathic pain syndromes found that the presence and severity of neuropathic pain was associated with impaired quality of life. ${ }^{15}$ Effective pain management can improve a pain patient's quality of life. In a study of 106 chronic non-malignant pain patients who agreed to participate in a medically supervised pain management program, quality of life significantly improved after one month of pain management over baseline scores. ${ }^{16}$ Recent studies investigating patient perceptions of the $5 \%$ lidocaine medicated plaster ${ }^{17}$ and the 7-day low-dose buprenorphine patch ${ }^{18}$ also found marked improvement in quality of life after 12 weeks of pain treatment.

\section{Pain management in clinical practice}

Pain is prevalent and widely under-treated. ${ }^{19,20}$ The World Health Organization (WHO) has advocated strongly for more liberal use of analgesic medicines ${ }^{21,22}$ and encourages national 
programs for relief of the most extreme forms of pain. ${ }^{23}$ Pain impairs a patient's quality of life, ${ }^{24}$ which improves when pain is effectively managed. ${ }^{25}$ Long-term pain is associated with cognitive impairment ${ }^{26,27}$ and depression. ${ }^{3}$ The effect of pain on patients is devastating, and the socioeconomic impact of chronic pain is overwhelming. ${ }^{24,28}$ In a study of chronic low back pain, patients had a significantly greater comorbidity burden than control patients including higher rates of depression and sleep disorders. ${ }^{29}$ These patients spent significantly more on drug therapy and had significantly higher total medical costs; annual medical costs were US\$ $8386 \pm 17,507$ compared with US\$ $3607 \pm 10,845$ for control patients.

Chronic pain negatively affects productivity, resulting in absenteeism from work, premature retirement, reduced ability to perform activities of everyday living, and presenteeism (a condition in which the pain patient reports to work but may not be able to fulfill his/her job duties completely). ${ }^{30} \mathrm{~A}$ recent study quantifying the costs of headaches in Europe (including health care expenses plus lost productivity) estimated costs of approximately 112 billion Euro annually. ${ }^{31}$ There are thus important personal, clinical, and social reasons to manage pain more effectively.

While acute and chronic pain syndromes must both be managed effectively, it is clear that chronic painful syndromes represent the greater individual and social burden. Acute pain does not always transition to chronic pain, but unmanaged, it can set the stage. Moreover, chronic pain can worsen when not managed promptly and effectively. Acute postsurgical pain may transition into long-term pain; a study of patients undergoing urologic surgery found that $51.2 \%$ reported pain 3 months after surgery. ${ }^{32}$ To prevent chronification or worsening of chronic pain, pain should be rapidly and accurately diagnosed and managed effectively. ${ }^{33}$ While most nurse-prescribers would agree with this statement, implementing it in daily practice can be challenging.

One important barrier to better pain management is the reticence of some patients to disclose pain. Some patients wait a considerable amount of time, even a year or more, before seeking medical care to help with pain. ${ }^{34} \mathrm{~A}$ patient's attitude toward pain and pain perceptions may be influenced by his or her culture, ${ }^{35}$ gender, ${ }^{36,37}$ socioeconomic factors, ${ }^{38,39}$ ethnic and religious attitudes, ${ }^{40}$ age, ${ }^{41}$ and the beliefs held by the patient or their family. ${ }^{42,43}$ Not all patients in pain will seek treatment, and factors such as culture and ethnicity can influence if and how much a patient will discuss painful symptoms. ${ }^{44,45}$ Thus, nurse-prescribers must be sensitive to patients who may be reticent to discuss their pain and encourage them to report all symptoms. In addition, further patient education is needed to assure patients that there are safe and effective ways to control or at least manage painful symptoms and that pain is not something they must simply endure.

Once a patient reports pain, it is important to assess that pain and its impact on the patient in an accurate manner. The most commonly used pain assessment tools include questionnaires (for both pain intensity and quality of life), patient interviews, a visual analog scale, and a numerical scale that allow the patient to quantify pain. Such tools are inherently subjective, but they are easy to use, inexpensive, and widely accepted. ${ }^{46}$ Using pictures (smiley faces) or observing behaviors associated with pain are often used for patients who cannot verbalize their pain, eg, the very young and those with cognitive impairment. ${ }^{47}$ Not only should the intensity of the pain be assessed, but also the quality of the pain, which can be important in identifying neuropathic pain or pain with a neuropathic component. ${ }^{48}$ For example, back pain with a neuropathic component has been shown to be associated with greater health care resource utilization and related costs than back pain without a neuropathic component. ${ }^{49}$

\section{Overview of pain management therapies \\ Nonpharmacological options}

Nonpharmacological options for pain management include massage, exercise, weight loss, diet, and relaxation techniques. ${ }^{50}$ Cognitive and behavioral therapies, as well as psychotherapy, biofeedback, and hypnotherapy may sometimes be effective. ${ }^{51-53}$ It is beyond the scope of this article to discuss nonpharmacological pain management in detail, but the authors agree that these can be very important as the foundation of a pain management plan. In some cases, a multidisciplinary approach to pain may be undertaken, involving a nurse, physician, physical therapist, occupational therapist, nutritionist, massage therapist, and other health care professionals. Complementary and alternative medical techniques, such as acupuncture, may be helpful for selected patients. ${ }^{54}$ Growing evidence supports the use of some complementary and alternative medical approaches in pain management, and a recent study found that $70 \%$ of arthritis patients were using some sort of complementary and alternative medical technique, although most did not disclose this in their medical history. ${ }^{55}$

\section{Topical analgesics}

Topical analgesics are available in gel, cream, or patch form, and are applied to the affected area. Many are available over-the-counter. Some examples are the 5\% lidocaine 
medicated plaster, ${ }^{56}$ the NSAIDs patches, such as the diclofenac epolamine patch, ${ }^{57}$ menthol, ${ }^{58}$ and essential oxygen oil. ${ }^{59,60}$ The advantages of topical products include localized delivery of medication, good evidence for efficacy, better tolerability due to less or no systemic action, and possible benefits in terms of patient adherence. ${ }^{61}$ The capsaicin patch, containing an $8 \%$ concentration of capsaicin, ${ }^{62}$ acts locally but not as an analgesic: a 30-60-minute application provides an improvement for several weeks/months by local nerve defunctionalization.

\section{Paracetamol and NSAIDs}

Paracetamol (also called acetaminophen in some geographical areas) is an aniline analgesic, with a well established presence in the pain armamentarium. Despite its familiarity, the exact mechanism of action of paracetamol remains to be thoroughly described..$^{63}$ Paracetamol at supratherapeutic doses has been associated with hepatic toxicity ${ }^{64}$ and is, in fact, a leading cause of serious liver injury. ${ }^{65,66}$ Weak evidence also reports hypertension as a possible side effect of paracetamol use, ${ }^{67-69}$ and a decrease in hemoglobin, ${ }^{70}$ and gastrointestinal side effects have been reported..$^{71}$ Maximum daily doses of oral paracetamol should not exceed $4 \mathrm{~g}$; however, in particular risk groups, such as patients with a history of alcohol abuse or existing liver disease, the use of paracetamol should be avoided. ${ }^{71,72}$

Although often discussed together with paracetamol, NSAIDs are a separate and diverse group of agents reducing prostaglandins and other chemical mediators which induce nociceptive activity and an inflammatory response. NSAIDs interrupt the biotransformation of prostaglandins and mediators in the arachidonic cascade by inhibiting cyclooxygenase (COX) isoenzymes. ${ }^{73}$ Nonselective NSAIDs block both COX-1 and COX-2, whereas selective NSAIDs (coxibs) inhibit COX-2. NSAIDs have dose-dependent toxicity, which may result in gastrointestinal symptoms and cardiorenal symptoms. ${ }^{74,75}$ Although NSAIDs can be effective pain relievers, a recent study associating NSAID use with increased risk of death from myocardial infarction ${ }^{76}$ indicates that they should be used cautiously in patients at risk for cardiovascular disease. These safety issues prompted recommendations to limit the exposure to NSAIDs to the "shortest possible duration at the lowest effective dose." "77 In the elderly, nonselective NSAIDs and selective COX-2 inhibitors should be used "rarely and with extreme caution in highly selected individuals," and elderly patients "with moderate to severe pain, pain-related functional impairment, or diminished quality of life due to pain, should be considered for opioid therapy." 78

\section{Opioids}

According to the WHO cancer pain ladder, opioids are grouped into step 2 (weak) and step 3 (strong) medications. Frequently prescribed weak opioids include codeine, dihydrocodeine, and tramadol, and frequently prescribed strong opioids are buprenorphine, fentanyl, hydromorphone, methadone, morphine, and oxycodone. Although being effective analgesics, opioid agents in general have been associated with certain dose-dependent adverse events, including nausea, vomiting, constipation, and somnolence. These side effects may occur in the majority of patients and can be treatment-limiting. ${ }^{79-81}$ In addition, opioids may be associated with tolerance, dependence, and addiction, and may lead to mood changes, hormonal changes, and an increased risk of fractures. ${ }^{81,82}$ Fractures likely result from an increased risk of falls and an effect of opioids on bone metabolism. ${ }^{81}$ Opioidinduced hyperalgesia has also been reported, a condition in which prolonged use of opioids lowers the pain threshold, paradoxically increasing the patient's pain, but this is not well understood. ${ }^{83,84}$ However, opioids differ in their risk profile; for instance, compared with hydrocodone, tramadol is associated with a reduced risk of fracture ${ }^{81}$ addiction, and dependence. ${ }^{85}$ In isolated cases, there have been reports of serotonin syndrome in a temporal connection with the therapeutic use of tramadol in combination with other serotoninergic medicinal products, such as selective serotonin reuptake inhibitors, or with monoamine oxidase inhibitors. ${ }^{86}$ Signs of serotonin syndrome include confusion, agitation, fever, sweating, ataxia, hyperreflexia, myoclonus, and diarrhoea. Withdrawal of the serotoninergic medicinal product usually brings about a rapid improvement. Treatment depends on the nature and severity of symptoms. ${ }^{86}$

\section{Combination products}

There is a need for treatment options which provide the analgesic efficacy of opioids but are better tolerated. Approaches are either to develop drugs with more than one mechanism of action, eg, tapentadol, which combines two analgesic principles, ie, $\mu$-opioid receptor agonism and noradrenalin reuptake inhibition, in one molecule, or to develop fixed combinations of analgesics with different mechanisms of action.

In selecting an analgesic agent, the WHO ladder may be helpful, but it is validated only in cancer pain. The WHO ladder recommends starting with nonopioid pain relievers, then progressing to weak and finally to strong opioids, based on pain intensity. The WHO paradigm conceives of analgesia as monotherapy. Combining two analgesic agents may provide an additive or synergistic effect of the two components. 
This can positively affect the analgesic efficacy of the drug; however, in some cases, it may amplify the side effect profile. ${ }^{87,88}$ A combination analgesic regimen may be considered especially effective when the individual agents have different analgesic mechanisms and act synergistically. ${ }^{9}$ There are a number of analgesics available combining two agents in one fixed-dose product. These fixed-dose combinations are convenient, reduce the pill burden, and may require lower dosages of the individual compounds. However, they are inflexible and may not provide ideal doses for particular patients. Many combination products use paracetamol. In order to avoid potential paracetamol overdose, patients must be aware of their daily cumulative paracetamol intake. Because paracetamol is found in over-the-counter combination products, as well as prescription combinations, and is available over-the-counter as a monotherapeutic agent, patients may exceed recommended cumulative doses ( $4 \mathrm{~g} /$ day or less ${ }^{72}$ ) whilst unaware of doing so, or may even be unaware of recommended doses. ${ }^{89}$ Nurse prescribers may play an important role in avoiding potentially fatal hepatotoxicity by informing and counseling patients on this point. Patients should be encouraged to inform their nurse prescribers about all additional over-the-counter medications, including paracetamol-containing cold remedies, which are frequently perceived as being harmless.

Examples of fixed-dose combinations containing an opioid include codeine-paracetamol, tramadol-paracetamol, and oxycodone-paracetamol. Synergistic analgesic benefits have been demonstrated for the fixed dose combination tramadolparacetamol. ${ }^{90,91}$ Management with a fixed-dose opioidnonopioid combination might require less opioid to achieve effective analgesia compared with opioid monotherapy. Opioid-sparing effects may reduce opioid-related side effects and limit the amount of narcotic drug required. Opioid-sparing was demonstrated in two studies comparing tramadolparacetamol with tramadol monotherapy in the management of subacute low back pain ${ }^{92}$ and pain following ambulatory hand surgery with intravenous regional anesthesia. ${ }^{93}$ Treatment with the fixed-dose combination reduced tramadol consumption by $24 \%$ in both studies, and resulted in significantly fewer side effects than with tramadol monotherapy.

Fixed-dose combination products have shown good efficacy and tolerability in the treatment of a number of acute and chronic pain syndromes. Table 2 summarizes the study results for pain syndromes relevant to the nurse-prescriber. The efficacy of fixed-dose tramadol-paracetamol for example was observed in a large noninterventional study in elderly patients ( $\geq 65$ years) attending general practices in France. ${ }^{94}$ More than half of the patients (65\%) experienced significant pain relief of their (mainly musculoskeletal) pain, the incidence of adverse events was low (4.5\%), and most patients (91\%) were satisfied with their treatment. In the elderly population, in whom conventional analgesics such as NSAIDs should be used with caution, ${ }^{78}$ a fixed-dose combination such as tramadol-paracetamol might be a useful treatment option for the nurse-prescriber.

\section{Therapeutic guidelines}

There is a wealth of literature about pain management, including guidelines addressing specific pain syndromes, ${ }^{72,78,111-124}$ but nurse-prescribers must put these guidelines into the context of a clinical practice at the front line of pain. Guidelines often address the large issues in pain, but may fail to consider matters crucial to nurse-prescribers, such as under-reporting of pain, mixed pain, and chronification. The authors note that, overall, guidelines tend to favor safety over pain relief. For example, the American Heart Association Scientific Statement recommends that patients with elevated cardiovascular risk factors suffering from musculoskeletal pain should avoid using certain pharmacological agents, even if it means that pain is undertreated. ${ }^{112}$ Because patient safety must always be paramount, analgesic options should be found which can safely yet effectively address pain. Not treating pain is not an option.

\section{Prescribing considerations for patients in pain}

Pain management must take into account the age, comorbidities, functional state, mental health, occupation, family status, and other aspects of the patient's life, as well as the type and anticipated duration of pain. Particular care is advised in treating pediatric and geriatric patients. A full medical history is required. In particular, the nurse-prescriber must be aware of all drugs the patient is taking, including herbal supplements and over-the-counter products. This may require specific inquiry. The more drugs a patient takes, the greater the likelihood of potentially dangerous drug-drug interactions. ${ }^{125}$ Paracetamol is safe and effective at recommended doses, but is associated with toxicity at high doses. ${ }^{126}$ Paracetamol poisoning can occur accidentally, in that patients may be unaware that paracetamol is contained in many prescription and over-the-counter products. Thus, while fixed-dose combination analgesic products using paracetamol may be effective, opioid-sparing, and safe, it is important to be aware of the patient's cumulative paracetamol dose. Nurse-prescribers can educate patients about the benefits and risks of paracetamol and help patients to understand cumulative paracetamol dosing. 


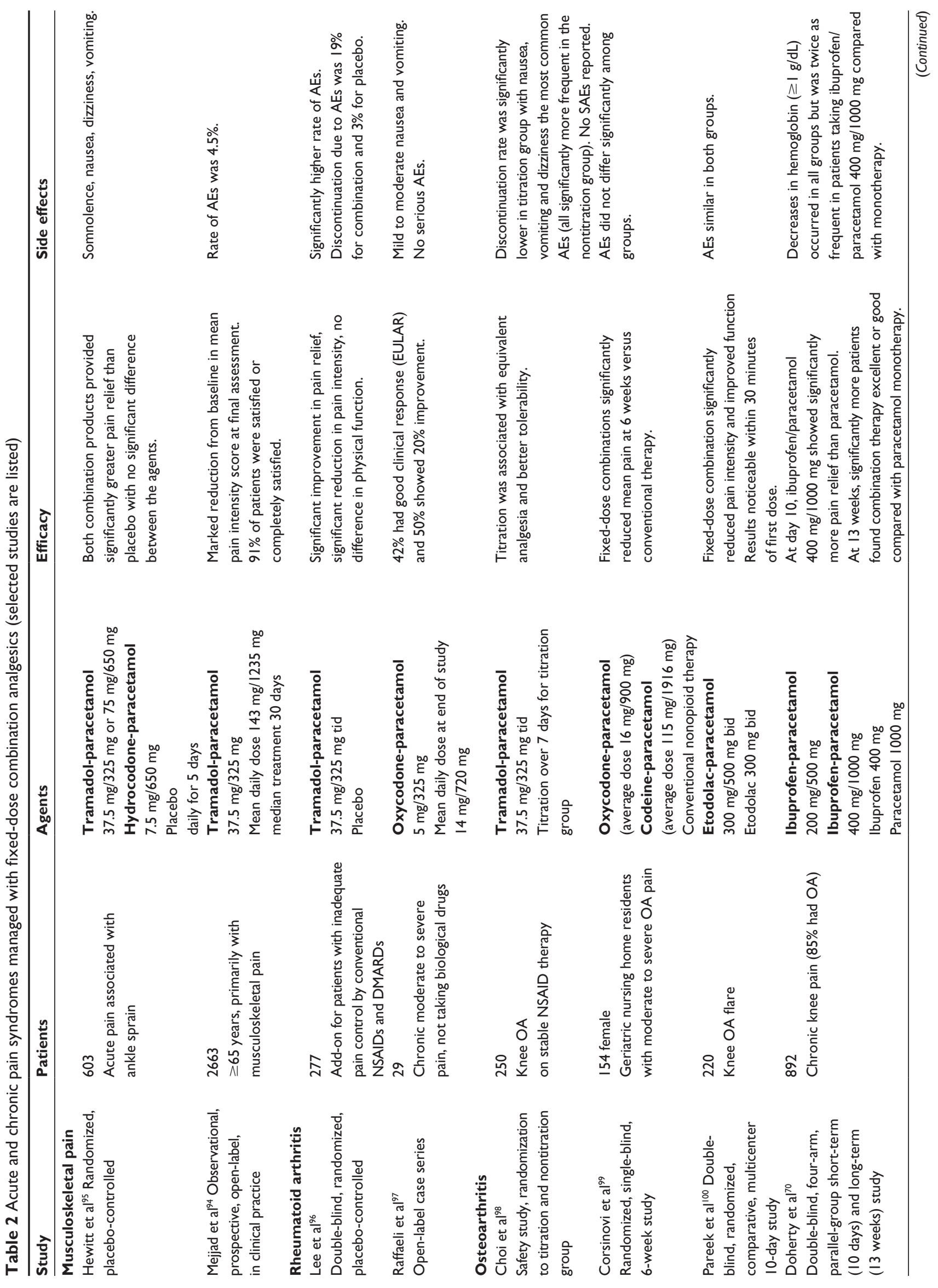



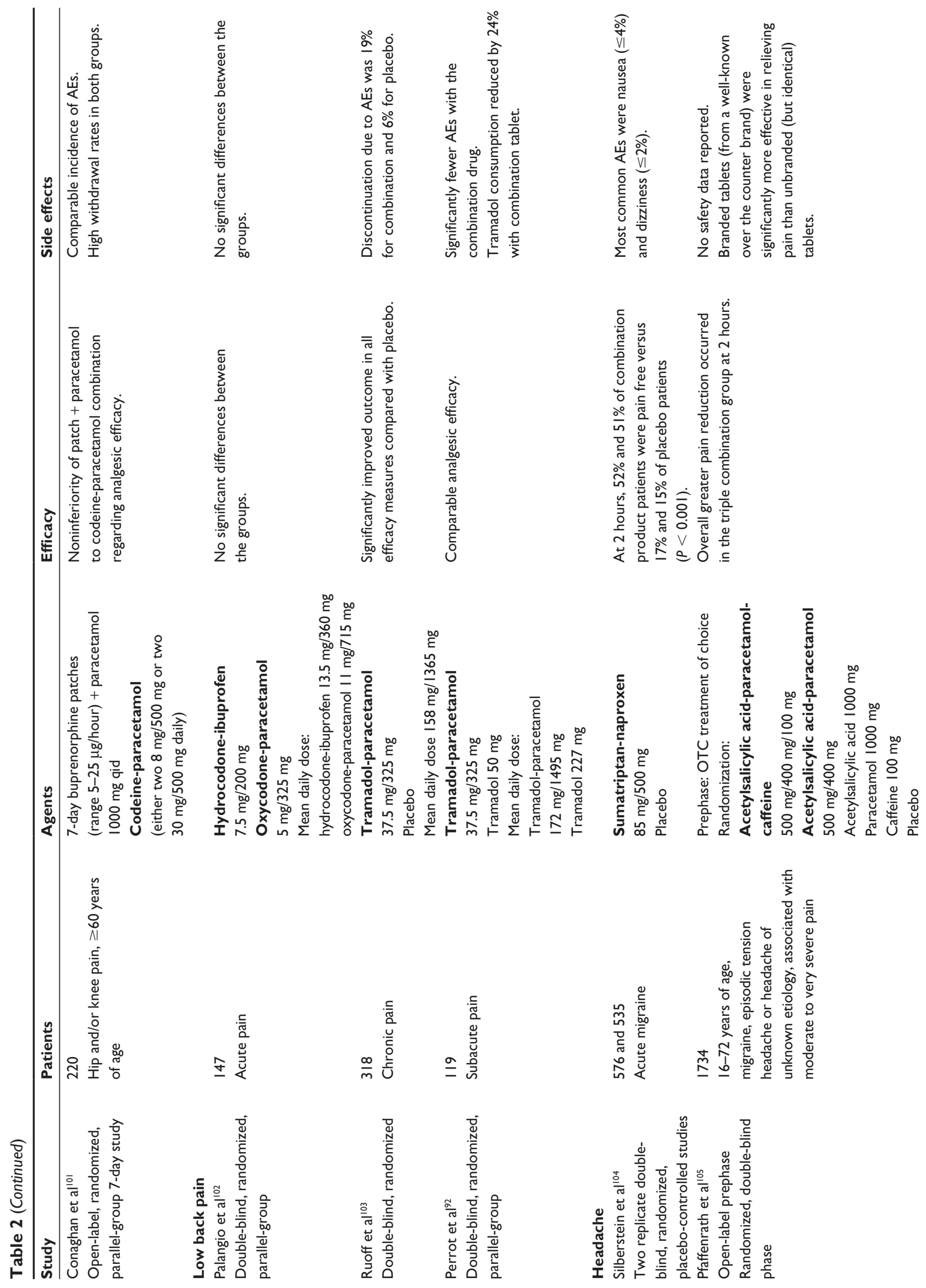

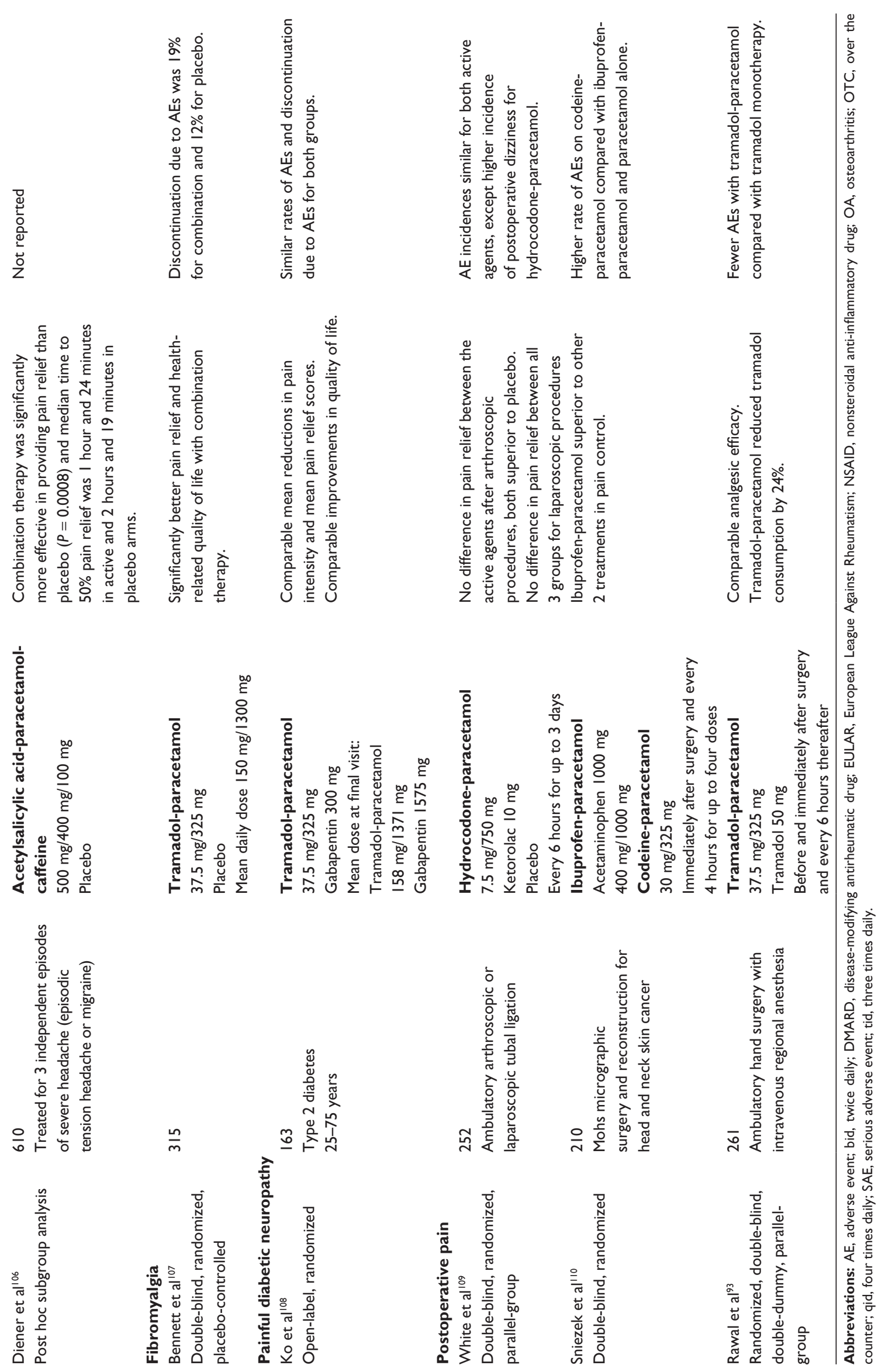


\section{Multimodal pain therapy}

Nurse-prescribers are increasingly recognizing the value of multimodal pain treatments for managing acute and chronic pain syndromes. A multimodal approach simply refers to the use of more than one treatment strategy to address pain. Conservative treatments may include rest, hot or cold therapy, exercise, diet changes, weight loss, smoking cessation, massage, physical therapy, occupational therapy, and others. There is growing evidence in the literature on complementary and alternative medicine techniques, which may offer relief with minimal risk to patients open to this type of treatment. Common complementary and alternative medicine therapy for pain includes acupuncture, aromatherapy, music therapy, and herbal supplements. ${ }^{54}$ Pharmacological pain treatment can then be added to this conservative base as needed, starting with nonopioid agents and progressing to fixed-dose combination products and, if necessary, to opioid therapy.

Patient education is an often neglected component in devising a comprehensive pain management plan for pain patients, and especially for those dealing with long-term or chronic pain. Patients should be encouraged to discuss their symptoms and questions about therapy with a qualified clinician or nurse. Patients on pharmacological therapy should be thoroughly informed about the drug(s) they are taking, dosing limits, potential side effects, and drug interactions.
An important component of multimodal pain therapy is the concept that there is no "magic pill". Some patients have the unrealistic expectation that they can simply take one tablet to relieve $100 \%$ of their pain. Patients should be encouraged to think of their pain and pain treatments in percentages. For example, regular massage may relieve about $20 \%$ of a patient's pain. Instead of dismissing this as insufficient, the patient should build on it. An exercise program may relieve another $30 \%$ of the patient's pain. Together, massage and exercise might therefore decrease the patient's pain by $50 \%$. If an analgesic product is then $50 \%$ effective, a multimodal therapeutic approach involving massage, exercise, and drug therapy could reduce $100 \%$ of the patient's pain. While this is an imperfect analogy, it may be a useful illustration to help patients understand better the fundamental concept underlying multimodal therapy.

\section{Positioning of fixed-dose combinations on the WHO cancer pain ladder}

Paradigms of pain management are often based on the older concept that all pain is nociceptive. The WHO cancer pain ladder ${ }^{127}$ describes pain and treatments based on pain intensity rather than the nature of the pain (Figure 3).

Over the years, several modifications have been proposed, including adaptations to accommodate other pain types. ${ }^{128}$



Figure 3 The World Health Organization pain ladder bases therapeutic choices on pain intensity and makes no provision of neuropathic or mixed pain syndromes.

Notes: *In fixed-dose combination products, such as oxycodone and paracetamol or hydrocodone and paracetamol; **considered a step 2 opioid but is also available in fixed-dose combination product of tramadol and paracetamol.

Adapted from World Health Organization pain ladder. ${ }^{127}$ 
Although created in 1986, the WHO pain ladder is still used to help clinicians understand the "ramp" of progressively stronger analgesics, but it is intended for cancer pain and does not apply well to some conditions like arthritis pain, where NSAIDs are more effective than opioids. Combination products, such as tramadol-paracetamol, were not available in 1986 and it is debatable as to where this and other fixeddose combination products would fit onto the original WHO ladder. Fixed-dose combination products are basically an unmarked rung on the ladder, because different experts might classify them as step 1 or step 2 analgesics, or between steps 1 and 2, if for instance a step 1 analgesic like paracetamol is combined with a step 2 opioid like tramadol.

\section{Conclusion}

Pain is a serious, prevalent, and frequently undertreated condition that can often be effectively and safely managed or even alleviated. Because pain is frequently multimechanistic, multimodal pain therapies including administration of a combination drug may be effective with good tolerability. The pharmacological armamentarium for pain is large and includes topical analgesics, nonopioid agents (such as paracetamol and NSAIDs), weak and strong opioids, and fixed-dose combination products. Proper product selection should take into account the patient's age, condition, type of pain, comorbidities, and balance safety with effectiveness. Fixed-dose combination products, such as tramadol-paracetamol, offer important advantages that a nurse-prescriber should consider, in that they may be opioidsparing without sacrificing efficacy. Pain should be treated promptly and effectively to restore the patient to full function, avoid pain chronification, and preserve quality of life.

\section{Disclosure}

JOB has received consultancy honoraria from Grünenthal $\mathrm{GmbH}$ and speaker honoraria from Pfizer Ireland. JVP has received consultancy honoraria from Grünenthal $\mathrm{GmbH}$, Baxter, Endo Pharmaceuticals, and Hospira. MvdL has received consultancy honoraria from Merck The Netherlands, Pfizer Europa, and Grünenthal GmbH, and speaker honoraria from Pfizer Europa. HUM has received consultancy honoraria from Grünenthal GmbH. IMM received consultancy honoraria from Boehringer Ingelheim, Grünenthal GmbH, Merck Sharp and Dohme Corporation, and Takeda Pharmaceuticals Europe, and has received lecture fees from Almirall, Astra-Zeneca, Boehringer Ingelheim, Bristol Myers Squibb, Esteve, Grünenthal GmbH, Eli Lilly and Company, Merck Sharp and Dohme Corporation, Novartis, and Sanofi-Aventis. SN has received consultancy honoraria or research grants from the following companies in the past five years: Grünenthal GmbH, Johnson and Johnson, Endo Pharmaceuticals, Cephalon, Alphapharma, King Pharmaceuticals, Allergan, ProStakan, and Covidien. SP has received consultancy honoraria from Grünenthal GmbH. RBR is a speaker, consultant, and/or basic science investigator for several pharmaceutical companies involved in analgesic research, but receives no royalty (cash or otherwise) from the sale of any product; he received consultancy honoraria from Grünenthal $\mathrm{GmbH}$. The meeting referred to herein was supported by Grünenthal GmbH, Aachen, Germany. The authors acknowledge editorial assistance from Jo Ann LeQuang (LeQ Medical, Angleton, TX), Elke Grosselindemann (Brett Medical Writing, Bibra Lake, Australia) and Birgit Brett (Brett Medical Writing, Pulheim, Germany). All costs associated with the publication of the manuscript were met by Grünenthal GmbH, Aachen, Germany.

\section{References}

1. Langley P. The prevalence, correlates and treatment of pain in the European Union. Curr Med Res Opin. 2011;27:463-480.

2. American Academy of Pain Medicine. AAPM Facts and Figures on Pain. 2011. Available from: http://www.painmed.org/patient/facts.html. Accessed July 5, 2011.

3. Breivik H, Collett B, Ventafridda V, Cohen R, Gallacher D. Survey of chronic pain in Europe: prevalence, impact on daily life, and treatment. Eur J Pain. 2006;10:287-333.

4. Brown S, Kirkpatrick M, Swansson M, McKenzie I. Pain experience in the elderly. Pain Manage Nurs. 2011;12:190-196.

5. Pergolizzi J, Ahlbeck K, Aldington D, et al. The chronic pain conundrum: should we CHANGE from relying on past history to assessing prognostic factors? Curr Med Res Opin. 2012;28: 249-256.

6. Treede RD, Jensen T, Campbell J, et al. Neuropathic pain: redefinition and a grading system for clinical and research purposes. Neurology. 2008;70:1630-1635.

7. Freynhagen R, Baron R. The evaluation of neuropathic components in low back pain. Curr Pain Headache Rep. 2009;13:185-190.

8. Friessem C, Willweber-Strumpf A, Zenz M. Chronic pain in primary care. German figures from 1991 and 2006. BMC Public Health. 2009; 9:299.

9. Raffa R. Pharmacology of oral combination analgesics: rational therapy for pain. J Clin Pharm Ther. 2001;26:257-264.

10. Elliott T, Renier C, Palcher J. Chronic pain, depression, and quality of life: correlations and predictive value of the SF-36. Pain Med. 2003; 4:331-339.

11. Becker N, Thomsen A, Olsen A, Sjogren P, Bech P, Eriksen J. Pain epidemiology and health related quality of life in chronic non-malignant pain patients referred to a Danish multidisciplinary pain center. Pain. 1997;73:393-400.

12. Hunfeld J, Perquin C, Duivenvoorden H, et al. Chronic pain and its impact on quality of life in adolescents and their families. $J$ Pediatr Psychol. 2001;26:145-153.

13. Lamé I, Peters M, Vlaeyen J, Kleef M, Patijn J. Quality of life in chronic pain is more associated with beliefs about pain, than with pain intensity. Eur J Pain. 2005;9:15-24.

14. Terwindt G, Ferrari M, Tijhuis M, Groenen A, Picavet J, Launer L. The impact of migraine on quality of life in the general population: the GEM study. Neurology. 2000;55:624-629. 
15. Jensen M, Chodroff M, Dworkin R. The impact of neuropathic pain on health-related quality of life: review and implications. Neurology. 2007;68:1178-1182.

16. Skevington SM, Carse MS, Williams AC. Validation of the WHOQOL100: pain management improves quality of life for chronic pain patients. Clin J Pain. 2001;17:264-275.

17. Überall M, Müller-Schwefe G. Patient perceptions associated with the $5 \%$ lidocaine medicate plaster in daily practice. Curr Med Res Opin. 2012;28:901-909.

18. Überall M, Müller-Schwefe G. Low-dose 7-day transdermal buprenorphine in daily clinical practice - perceptions of patients with moderate nonmalignant chronic pain. Curr Med Res Opin. 2012;28: $1585-1595$.

19. Varrassi G, Müller-Schwefe G, Pergolizzi J, et al. Pharmacological treatment of chronic pain - the need for CHANGE. Curr Med Res Opin. 2010;26:1231-1245.

20. Ott B. Progress in ethical decision making in the care of the dying. Dimens Crit Care Nurs. 2010;29:73-80.

21. World Health Organization. Achieving Balance in National Opioids Control Policy - Guidelines for Assessment. Geneva, Switzerland: World Health Organization; 2000.

22. World Health Organization. Cancer pain relief with a guide to opioid availability. 1996. Available from: http://www.painpolicy.wisc.edu/ publicat/11WHOGLs/WHOGLs.pdf. Accessed May 12, 2011.

23. World Health Organization. National Cancer Control Programmes: Policies and Management Guidelines. Geneva, Switzerland: World Health Organization; 2002.

24. Langley P, Müller-Schwefe G, Nicolaou A, Liedgens H, Pergolizzi J, Varrassi G. The societal impact of pain in the European Union: healthrelated quality of life and healthcare resource utilization. J Med Econ. 2010;13:571-581.

25. Robbins L. Refractory chronic migraine: long-term follow-up using a refractory rating scale. J Headache Pain. 2012;13:225-229.

26. Kreitler S, Niv D. Cognitive impairment in chronic pain. Pain Clin Updates. 2007;15:1-4.

27. Lee DM, Pendleton N, Tajar A, et al. Chronic widespread pain is associated with slower cognitive processing speed in middle-aged and older European men. Pain. 2010;151:30-36.

28. Langley P, Müller-Schwefe G, Nicolaou A, Liedgens H, Pergolizzi J, Varrassi G. The impact of pain on labor force participation, absenteeism and presenteeism in the European Union. J Med Econ. 2010;13: $662-672$.

29. Gore M, Sadosky A, Stacey BR, Tai KS, Leslie D. The burden of chronic low back pain: clinical comorbidities, treatment patterns, and healthcare costs in usual care settings. Spine (Phila Pa 1976). 2012;37: E668-E677.

30. Bansback N, Zhang W, Walsh D, et al. Factors associated with absenteeism, presenteeism and activity impairment in patients in the first years of RA. Rheumatology (Oxford). 2012;51:375-384.

31. Linde M, Gustavsson A, Stovner LJ, et al. The cost of headache disorders in Europe: the Eurolight project. Eur J Neurol. 2012;19:703-711.

32. Ozgur E, Straub K, Wille S, Engelmann U, Dagtekin O, Gerbershagen HJ. Impact of preoperative pain on postoperative pain chronification. Six-month follow-up after urologic surgery. Urologe A. 2011;50: 1396-1402. German.

33. Bigal ME, Lipton RB. Migraine chronification. Curr Neurol Neurosci Rep. 2011;11:139-148.

34. Woolf A, Zeidler H, Haglund U, et al. Musculoskeletal pain in Europe: its impact and a comparison of population and medical perceptions of treatment in eight European countries. Ann Rheum Dis. 2004;63: 342-347.

35. Ferreira-Valente MA, Ribeiro JL, Jensen MP, Almeida R. Coping with chronic musculoskeletal pain in Portugal and in the United States: a cross-cultural study. Pain Med. 2011;12:1470-1480.

36. Wise EA, Price DD, Myers CD, Heft MW, Robinson ME. Gender role expectations of pain: relationship to experimental pain perception. Pain. 2002;96:335-342.
37. Fillingim RB. Sex, gender, and pain: women and men really are different. Curr Rev Pain. 2000;4:24-30.

38. Kocoglu D, Ozdemir L. The relation between pain and pain beliefs and sociodemographic-economic characteristics in an adult population. Agri. 2011;23:64-70. Turkish.

39. Davies KA, Silman AJ, Macfarlane GJ, et al. The association between neighbourhood socio-economic status and the onset of chronic widespread pain: results from the EPIFUND study. Eur J Pain. 2009;13: 635-640.

40. Defrin R, Eli I, Pud D. Interactions among sex, ethnicity, religion, and gender role expectations of pain. Gend Med. 2011;8:172-183.

41. Gibson S, Helme R. Age-related differences in pain perception and report. Clin Geriatr Med. 2001;17:433-456.

42. Wilson AC, Lewandowski AS, Palermo TM. Fear-avoidance beliefs and parental responses to pain in adolescents with chronic pain. Pain Res Manag. 2011;16:178-182.

43. Meeker MA, Finnell D, Othman AK. Family caregivers and cancer pain management: a review. J Fam Nurs. 2011;17:29-60.

44. Katz JN, Lyons N, Wolff LS, et al. Medical decision-making among Hispanics and non-Hispanic whites with chronic back and knee pain: a qualitative study. BMC Musculoskelet Disord. 2011;12:78.

45. Edwards RR, Moric M, Husfeldt B, Buvanendran A, Ivankovich O. Ethnic similarities and differences in the chronic pain experience: a comparison of african american, Hispanic, and white patients. Pain Med. 2005;6:88-98.

46. Breivik H, Borchgrevink PC, Allen SM, et al. Assessment of pain. Br J Anaesth. 2008;101:17-24.

47. Ni Thuathail A, Welford C. Pain assessment tools for older people with cognitive impairment. Nurs Stand. 2011;26:39-46.

48. Freynhagen R, Wirz S, Rolke R. Diagnosis of neuropathic pain. Ther Umsch. 2011;68:495-500. German.

49. Mehra M, Hill K, Nicholl D, Schadrack J. The burden of chronic low back pain with and without a neuropathic component: a healthcare resource use and cost analysis. J Med Econ. 2012;15:245-252.

50. Park J, Hughes AK. Nonpharmacological approaches to the management of chronic pain in community-dwelling older adults: a review of empirical evidence. J Am Geriatr Soc. 2012;60:555-568.

51. Thieme K, Gracely R. Are psychological treatments effective for fibromyalgia pain? Curr Rheum Rep. 2009;11:443-450.

52. Kasper S. The psychiatrist confronted with a fibromyalgia patient. Hum Psychopharmacol. 2009;24 Suppl 1:S25-S30.

53. Yaster M, Kost-Byerly S, Maxwell L. The management of pain in sickle cell disease. Ped Clin N Amer. 2000;47:699-710.

54. Molsberger A. Acupuncture in orthopedics. Orthopade. 2012;41:100-105. German.

55. Rispler D, Sara J, Davenport L, Mills B, Iskra C. Underreporting of complementary and alternative medicine use among arthritis patients in an orthopedic clinic. Am J Orthop (Belle Mead NJ). 2011;40:E92-E95.

56. Mick G, Correa-Illanes G. Topical pain management with the $5 \%$ lidocaine medicated plaster - a review. Curr Med Res Opin. 2012;28: 937-951.

57. Lionberger D, Brennan M. Topical nonsteroidal anti-inflammatory drugs for the treatment of pain due to soft tissue injury: diclofenac epolamine topical patch. J Pain Res. 2010;3:223-233.

58. Gaudioso C, Hao J, Martin-Eauclaire MF, Gabriac M, Delmas P. Menthol pain relief through cumulative inactivation of voltage-gated sodium channels. Pain. 2012;153:473-484.

59. Pergolizzi J, Pappagallo M, Raffa R, et al. Preliminary observations of a novel topical oil with analgesic properties for treatment of acute and chronic pain syndromes. Pain Pract. 2010;10:201-213.

60. Taylor R Jr, Gan TJ, Raffa RB, et al. A randomized, double-blind comparison shows the addition of oxygenated glycerol triesters to topical mentholated cream for the treatment of acute musculoskeletal pain demonstrates incremental benefit over time. Pain Pract. February 5, 2012. [Epub ahead of print.]

61. Jorge LL, Feres CC, Teles VE. Topical preparations for pain relief: efficacy and patient adherence. J Pain Res. 2011;4:11-24. 
62. Anand P, Bley K. Topical capsaicin for pain management: therapeutic potential and mechanisms of action of the new high-concentration capsaicin 8\% patch. Br J Anaesth. 2011;107:490-502.

63. Toussaint K, Yang X, Zielinski M, et al. What do we (not) know about how paracetamol (acetaminophen) works? J Clin Pharm Ther. 2010; 35(6):617-638.

64. James L, Letzig L, Simpson P, et al. Pharmacokinetics of acetaminophen-protein adducts in adults with acetaminophen overdose and acute liver failure. Drug Metab Dispos. 2009;37:1779-1784.

65. Bower W, Johns M, Margolis H, Williams I, Bell B. Population-based surveillance for acute liver failure. Am J Gastroenterol. 2007;102: 2459-2463.

66. Bronstein A, Spyker D, Cantilena L, Green J, Rumack B, Griffin S. 2008 annual report of the American Association of Poison Control Centers' national poison data system (NPDS): 26th annual report. Clin Toxicol. 2009;47:911-1084.

67. Sudano I, Flammer A, Périat D, et al. Acetaminophen increases blood pressure in patients with coronary artery disease. Circulation. 2010;122: 1789-1796.

68. Montgomery B. Does paracetamol cause hypertension? BMJ. 2008;336:1190-1191.

69. White W, Campbell P. Blood pressure destabilization on nonsteroidal antiinflammatory agents: acetaminophen exposed? Circulation. 2010; 122:1779-1781.

70. Doherty M, Hawkey C, Goulder M, et al. A randomised controlled trial of ibuprofen, paracetamol or a combination tablet of ibuprofen/ paracetamol in community-derived people with knee pain. Ann Rheum Dis. 2011;70:1534-1541.

71. Zhang W, Nuki G, Moskowitz R, et al. OARSI recommendations for the management of hip and knee osteoarthritis: part III: Changes in evidence following systematic cumulative update of research published through January 2009. Osteoarthritis Cartilage. 2010;18: 476-499.

72. Altman R. Practical considerations for the pharmacologic management of osteoarthritis. Am J Manag Care. 2009;15:S236-S243.

73. Rao P, Knaus E. Evolution of nonsteroidal anti-inflammatory drugs (NSAIDs): cyclooxygenase (COX) inhibition and beyond. J Pharm Pharm Sci. 2008;11:81s-110s.

74. Ng S, Chan F. NSAID-induced gastrointestinal and cardiovascular injury. Curr Opin Gastroenterol. 2010;26:611-617.

75. Lanas A, Perez-Aisa M, Feu F, et al. A nationwide study of mortality associated with hospital admission due to severe gastrointestinal events and those associated with nonsteroidal antiinflammatory drug use. Am J Gastroenterol. 2005;100:1685-1693.

76. Schjerning-Olsen A, Fosbøl E, Lindhardsen J, et al. Duration of treatment with nonsteroidal anti-inflammatory drugs and impact on risk of death and recurrent myocardial infarction in patients with prior myocardial infarction: a nationwide cohort study. Circulation. 2011;123: 2226-2235.

77. European Medicines Agency. Opinion of the committee for medicinal products for human use pursuant to the article 5(3) of regulation (EC) no 726/2004, for nonselective non-steroidal anti-inflammatory drugs (NSAIDs). 2006. Available from: http://www.ema.europa.eu/docs/ en_GB/document_library/Other/2010/01/WC500054342.pdf. Accessed March 11, 2012.

78. American Geriatric Society Panel on the Pharmacological Management of Persistent Pain in Older Persons. Pharmacological management of persistent pain in older persons. J Am Geriatr Soc. 2009;57: 1331-1346.

79. Anastassopoulos KP, Chow W, Ackerman SJ, Tapia C, Benson C, Kim MS. Oxycodone-related side effects: impact on degree of bother, adherence, pain relief, satisfaction, and quality of life. J Opioid Manag. 2011;7:203-215

80. Rosti G, Gatti A, Costantini A, Sabato AF, Zucco F. Opioid-related bowel dysfunction: prevalence and identification of predictive factors in a large sample of Italian patients on chronic treatment. Eur Rev Med Pharmacol Sci. 2010;14:1045-1050.
81. Solomon D, Rassen J, Glynn R, Lee J, Levin R, Schneeweiss S. The comparative safety of analgesics in older adults with arthritis. Arch Intern Med. 2010;170:1968-1976.

82. Sullivan M, Von Korff M, Banta-Green C, Merrill J, Saunders K. Problems and concerns of patients receiving chronic opioid therapy for chronic non-cancer pain. Pain. 2010;149:345-353.

83. Passero C, McCaffery M. Opioid-induced hyperalgesia. J Perianesth Nurs. 2012;27:46-50.

84. Raffa R, Pergolizzi J. Opioid-induced hyperalgesia: is it clinically relevant for the treatment of pain patients? Pain Manag Nurs. 2012. In press.

85. Adams E, Breiner S, Cicero T, et al. A comparison of the abuse liability of tramadol, NSAIDs, and hydrocodone in patients with chronic pain. J Pain Symptom Manage. 2006;31:465-476.

86. Tramadol hydrochloride $50 \mathrm{mg}$ capsules. The Electronic Medicines Compendium. 2011. Available from: http://www.medicines.org.uk/ emc/medicine/24186/SPC/tramadol\%20hydrochloride $\% 2050 \mathrm{mg} \% 20$ capsules/. Accessed December 15, 2011.

87. Raffa R. Pharmacological aspects of successful long-term analgesia. Clin Rheumatol. 2006;25 Suppl 1:S9-S15.

88. Raffa R, Clark-Vetri R, Tallarida R, Wertheimer A. Combination strategies for pain management. Expert Opin Pharmacother. 2003;4: 1697-1708.

89. Schilling A, Corey R, Leonard M, Eghtesad B. Acetaminophen: old drug, new warnings. Cleve Clin J Med. 2010;77:19-27.

90. Raffa R, Friderichs E, Reimann W, Shank R, Codd E, Vaught J. Opioid and nonopioid components independently contribute to the mechanism of action of tramadol, an 'atypical' opioid analgesic. J Pharmacol Exp Ther. 1992;260:275-285.

91. Filitz J, Ihmsen H, Günther W, et al. Supra-additive effects of tramadol and acetaminophen in a human pain model. Pain Manag Nurs. 2008; 136:262-270.

92. Perrot S, Krause D, Crozes P, Naim C. Efficacy and tolerability of paracetamol/tramadol (325 mg/37.5 mg) monotherapy in patients with subacute low back pain: a multicenter, randomized, double-blind, parallelgroup, 10-day treatment study. Clin Ther. 2006;28:1592-1606.

93. Rawal N, Macquaire V, Catala E, Berti M, Costa R, Wietlisbach M. Tramadol/paracetamol combination tablet for postoperative pain following ambulatory hand surgery: a double-blind, double-dummy, randomized, parallel-group trial. J Pain Res. 2011;4:103-110.

94. Mejjad O, Serrie A, Ganry H. Epidemiological data, efficacy and safety of a paracetamol-tramadol fixed combination in the treatment of moderate-to-severe pain. SALZA: a post-marketing study in general practice. Curr Med Res Opin. 2011;27:1013-1020.

95. Hewitt D, Todd K, Xiang J, Jordan D, Rosenthal N. Tramadol/ acetaminophen or hydrocodone/acetaminophen for the treatment of ankle sprain: a randomized, placebo-controlled trial. Ann Emerg Med. 2007;49:468-480.

96. Lee E, Lee E, Park B, et al. Tramadol 37.5-mg/acetaminophen 325-mg combination tablets added to regular therapy for rheumatoid arthritis pain: a 1-week, randomized, double-blind, placebo-controlled trial. Clin Ther. 2006;28:2052-2060.

97. Raffaeli W, Pari C, Corvetta A, et al. Oxycodone/acetaminophen at low dosage: an alternative pain treatment for patients with rheumatoid arthritis. J Opioid Manag. 2010;6:40-46.

98. Choi C, Song J, Kang Y, et al. A 2-week, multicenter, randomized, double-blind, double-dummy, add-on study of the effects of titration on tolerability of tramadol/acetaminophen combination tablet in Korean adults with knee osteoarthritis pain. Clin Ther. 2007;29:1381-1389.

99. Corsinovi L, Martinelli E, Fonte G, et al. Efficacy of oxycodone/ acetaminophen and codeine/acetaminophen vs conventional therapy in elderly women with persistent, moderate to severe osteoarthritisrelated pain. Arch Gerontol Geriatr. 2009;49:378-382.

100. Pareek A, Chandurkar N, Ambade R, Chandanwale A, Bartakke G. Efficacy and safety of etodolac-paracetamol fixed dose combination in patients with knee osteoarthritis flare-up: a randomized, double-blind comparative evaluation. Clin J Pain. 2010;26:561-566. 
101. Conaghan P, O’Brien C, Wilson M, Schofield J. Transdermal buprenorphine plus oral paracetamol vs an oral codeine-paracetamol combination for osteoarthritis of hip and/or knee: a randomised trial. Osteoarthritis Cartilage. 2011;19:930-938.

102. Palangio M, Morris E, Doyle RJ, Dornseif B, Valente T. Combination hydrocodone and ibuprofen versus combination oxycodone and acetaminophen in the treatment of moderate or severe acute low back pain. Clin Ther. 2002;24:87-99.

103. Ruoff G, Rosenthal N, Jordan D, Karim R, Kamin M. Tramadol/ acetaminophen combination tablets for the treatment of chronic lower back pain: a multicenter, randomized, double-blind, placebo-controlled outpatient study. Clin Ther. 2003;25:1123-1141.

104. Silberstein SD, Mannix LK, Goldstein J, et al. Multimechanistic (sumatriptan-naproxen) early intervention for the acute treatment of migraine. Neurology. 2008;71:114-121.

105. Pfaffenrath V, Diener HC, Pageler L, Peil H, Aicher B. OTC analgesics in headache treatment: open-label phase vs randomized double-blind phase of a large clinical trial. Headache 2009;49:638-645.

106. Diener HC, Peil H, Aicher B. The efficacy and tolerability of a fixed combination of acetylsalicylic acid, paracetamol, and caffeine in patients with severe headache: a post-hoc subgroup analysis from a multicentre, randomized, double-blind, single-dose, placebocontrolled parallel group study. Cephalalgia. 2011;31:1466-1476.

107. Bennett R, Kamin M, Kamin R, Rosenthal N. Tramadol and acetaminophen combination tablets in the treatment of fibromyalgia pain: a double-blind, randomized, placebo-controlled study. Am J Cardiol. 2003;114:537-545.

108. Ko S, Kwon H, Yu J, et al. Comparison of the efficacy and safety of tramadol/acetaminophen combination therapy and gabapentin in the treatment of painful diabetic neuropathy. Diabet Med. 2010;27: 1033-1040.

109. White P, Joshi G, Carpenter R, Fragen R. A comparison of oral ketorolac and hydrocodone-acetaminophen for analgesia after ambulatory surgery: arhroscopy versus laparoscopic tubal ligation. Anesth Analg. 1997;85:37-43.

110. Sniezek P, Brodland D, Zitelli J. A randomized controlled trial comparing acetaminophen, acetaminophen and ibuprofen, and acetaminophen and codeine for postoperative pain relief after Mohs surgery and cutaneous reconstruction. Dermatol Surg. 2011;37:1007-1013.

111. Zhang W, Moskowitz R, Nuki G, et al. OARSI recommendations for the management of hip and knee osteoarthritis, Part II: OARSI evidence-based, expert consensus guidelines. Osteoarthritis Cartilage. 2008; $16: 137-162$

112. Antman E, Bennett J, Daugherty A, Furberg C, Roberts H, Taubert K. Use of nonsteroidal antiinflammatory drugs: an update for clinicians: a scientific statement from the American Heart Association. Circulation. 2007;115:1634-1642.

113. National Institute for Health and Clinical Excellence. The care and management of osteoarthritis in adults. 2008. Available from: http:// www.nice.org.uk/nicemedia/pdf/CG59NICEguideline.pdf. Accessed December 15, 2010.

114. Schnitzer T. Update on guidelines for the treatment of chronic musculoskeltal pain. Clin Rheumatol. 2006;25 Suppl 1:S22-S29.

115. Altman R. Early management of osteoarthritis. Am J Manag Care. 2010;16:S41-S47.
116. NICE. Rheumatoid arthritis: the management of rheumatoid arthritis in adults. NICE Clinical Guideline 2009. Available from: http:// www.nice.org.uk/nicemedia/live/12131/43327/43327.pdf. Accessed December 18, 2010.

117. Luqmani R, Hennell S, Estrach C, et al. British Society for Rheumatology and British Health Professionals in Rheumatology guideline for the management of rheumatoid arthritis (the first two years). Rheumatology (Oxford). 2006;45:1167-1169.

118. Luqmani R, Hennell S, Estrach C, et al. British Society for Rheumatology and British Health Professionals in Rheumatology guideline for the management of rheumatoid arthritis (after the first 2 years). Rheumatology (Oxford). 2009;48:436-439.

119. Combe B, Landewe R, Lukas C, et al. EULAR recommendations for the management of early arthritis: report of a task force of the European Standing Committee for International Clinical Studies Including Therapeutics (ESCISIT). Ann Rheum Dis. 2007;66:34-45.

120. Carville S, Arendt-Nielsen S, Bliddal H, et al. EULAR evidence-based recommendations for the management of fibromyalgia syndrome. Ann Rheum Dis. 2008;67:536-541.

121. Buckhardt C, Goldenberg D, Crofford L, et al. Guideline for the management of fibromyalgia syndrome pain in adults and children. Clinical practice guideline no. 4. 2005. Available from: http://www. ampainsoc.org/pub/fibromyalgia.htm. Accessed December 18, 2010.

122. Airaksinen O, Brox J, Cedraschi C, et al. Chapter 4. European guidelines for the management of chronic nonspecific low back pain. Eur Spine J. 2006;15 Suppl 2:S192-S300.

123. Chou R, Hoyt-Huffman L. Medications for acute and chronic low back pain: a review of the evidence for an American Pain Society/ American College of Physicians clinical practice guideline. Ann Intern Med. 2007;147:505-514.

124. National Institute for Health and Clinical Excellence. Low back pain: early management of persistent non-specific low back pain. 2009. Available from: http://www.nice.org.uk/nicemedia/live/11887/44343/44343. pdf. Accessed December 18, 2010.

125. Pergolizzi J, Labhsetwar S, Puenpatom R, Joo S, Ben-Joseph R, Summers K. Prevalence of exposure to potential CYP450 pharmacokinetic drug-drug interactions among patients with chronic low back pain taking opioids. Pain Pract. 2011;11:230-239.

126. Daly F, Fountain J, Murray L, Graudins A, Buckley N. Guidelines for the management of paracetamol poisoning in Australia and New Zealand - explanation and elaboration. A consensus statement from clinical toxicologists consulting to the Australasian poisons information centres. Med J Aust. 2008;188:296-301.

127. World Health Organization. WHO's pain ladder. 1986. Available from: http://www.who.int/cancer/palliative/painladder/en/. Accessed June $15,2012$.

128. Vargas-Schaffer G. Is the WHO analgesic ladder still valid? Can Fam Physician. 2010;56:514-517.

129. Pergolizzi J, Alegre C, Blake D, et al. Current considerations for the treatment of severe chronic pain: the potential for tapentadol. Pain Pract. 2012;12:290-306.
Nursing: Research and Reviews

\section{Publish your work in this journal}

Nursing: Research and Reviews is an international, peer-reviewed, open access journal publishing original research, reports, reviews and commentaries on all aspects of nursing and patient care. These include patient education and counselling, ethics, management and organizational issues, diagnostics and prescribing, economics and

\section{Dovepress}

resource management, health outcomes, and improving patient safety in all settings. The manuscript management system is completely online and includes a very quick and fair peer-review system. Visit http://www.dovepress.com/testimonials.php to read real quotes from published authors. 